\title{
Promoting Language Learners' Awareness of Autonomy Through Goal Setting - An Alternative Approach of Assessing Goal Setting Effects
}

\author{
Shih Huei-Ju ${ }^{1}$ \\ ${ }^{1}$ School of Literature, National Changhua University of Education, Changhua, Taiwan \\ Correspondence: Shih Huei-Ju, School of Literature, National Changhua University of Education, No.1, Jin-De \\ Road, Changhua City, Changhua, Taiwan. Tel: 886-935-580-868. E-mail: beckeystone@gmail.com
}

Received: July 29, 2018 Accepted: September 11, 2018 Online Published: September 13, 2018

doi: 10.5539/elt.v11n10p52 URL: http://doi.org/10.5539/elt.v11n10p52

\begin{abstract}
This article aims at proposing a new measurement to assess the effects of language learners' goal-setting behavior, as an alternative to the traditional open-ended questionnaire. This goal-setting instrument was carefully developed through three phases. In the first phase, an item pool was generated. In the second phase, a pilot study was carried out with a view to modifying the weak points of the questionnaire. In the third phase, a final version of the questionnaire was distributed among participants for evaluating the practicality. The evaluation of the psychometric properties of the final instrument was made using confirmatory factor analyses (CFA), with the validity and reliability being evaluated. The results indicate that the proposed instrument yields satisfactory characteristics and that the theoretical model bears a good fit with the data. The researcher proposes that the instrument presented in this study can provide a more psychometrically sound measure of goal-setting in learning a second language than traditional open-ended questionnaires.
\end{abstract}

Keywords: second language learning, goal-setting, questionnaire design, quantitative analysis, teaching and learning

\section{Introduction}

It is increasingly recognized that setting goals is perceived to be a critical component of success and is used in many areas, such as careers, health care, and school subjects. For students to get better performance, setting personal goals is widely suggested. However, few learners have ever considered referring to the theoretical foundation before setting goals. Therefore, research on the effects of goal-setting has been criticized to be "shaky" (Manchon, Rocade Larios, \& Murphy, 2007, p. 230). The reason may be that most empirical goal-setting studies related to language learning have adopted an open-ended questionnaire (e.g. Kato, 2009) as a qualitative research tool. In contrast, there was little explicit exploration of evaluating the outcomes of applying goal-setting theory to language learning in a quantitative manner. Moreover, the multiple dimensions of goal-setting theory has not yet been empirically investigated in the context of EFL. Owing to the open-ended and customized traits of the questionnaire, the instrument of goal-setting research cannot be generalized across all settings (e.g., Azar et al., 2014, Kato, 2009). The present study seeks to develop a new questionnaire within the EFL context to assess learners' learning performance through goal setting. With the aim of validating a newly developed instrument, a Likert scaled questionnaire on language learning objectives was developed to quantify the results. Confirmatory factor analysis (CFA) using structural equation modeling (SEM) was utilized to assess validity and reliability. The multidimensional features of the goal-setting were also investigated.

\subsection{Goal-setting Theory for Language Learning and Its Multidimensional Perspectives}

Goal-setting theory was first proposed by Locke (1966). It describes the association between setting goals and individual's behavior. The main foci were on an individual's choice of goals, the motivation of reaching the goals, and the possibility of the goals being achieved (Latham \& Locke, 2006). In the theory, two main elements are involved: the uniqueness and difficulty of the goal, and the effort required to achieve the goals (Locke \& Latham, 1990a). In other words, if the goal is of high specificity, it will be more likely to be achieved. Furthermore, if the commitment to the goal is high, the possibility of achieving it will be high. The definition of a goal, according to goal-setting theory, is what an individual intentionally attempts to do. It is expected that 
setting a learning objective will benefit learners, and is taken as one of the most effective ways to ameliorate performance (Burton et al., 2010).

In their study, Latham and Locke (2006) claims that four facilitators to boost goal-setting effects. They are (1) feedback, a tool for people to monitor their progress; (2) commitment to the goal, enhanced by personal self-efficacy and of great value to the goal; (3) task complexity, the degree to which work knowledge being difficult to be acquired; (4) situational constraints, in which the situation influences the intensity of effort one put into goals. With deeper inspections, the four major facilitators-feedback, commitment to the goal, task complexity, and situational constraints - can be put into the following dimensions, (1) social-behavioral \& motivational, (2) cognitive \& motivational, (3) metacognitive \& cognitive, and (4) environmental, respectively.

A closer look may explain this categorization. First, social-behavioral strategies refer to efforts of controlling learning behavior from the influence of environment (Zimmerman, 1989, 2011). Since goal-setting theory emphasizes the significance of feedback circuits in which learners monitor the development of tasks, assess the performance, and modify strategies, goals, as well as motivational factors accordingly (Zimmerman, 2013), this facilitator "feedback" falls in the social-behavioral dimension. Another dimension which feedback falls in is motivational, because receiving feedback is a process or thought that is intentionally used by learners to maintain or increase their dedication (Wolters, 1999). Feedback determines whether the learner is willing to remain motivated or not. Second, the facilitator "commitment to the goal" pertains to the cognitive domain. Cognitive strategies mean the skill that a learner adopt to deal with when performing a task (Pintrich et al., 1991). These strategies help students to construct and practice their knowledge. Such processes require the efforts that learners make when they dedicate themselves to the commitment to the goals. Hence the facilitator "commitment to the goal" is categorized as cognitive strategies. Third, the facilitator "task complexity" subsumes the traits of metacognitive and cognitive strategies. It takes the metacognitive ability to accomplish the goals. Dörnyei and Otto (1998) distributed motivated behavior into three stages: (1) pre-actional, (2) actional, and (3) post-actional. According to Dörnyei and Otto's (1998) taxonomy, goal-setting belongs to the pre-actional phase and elicits the metacognitive concept (Locke et al., 1981; Wenden, 1991; Yang, 1998), because metacognitive strategies indicate the skills control learners' cognition to meet the demands of particular tasks (Winne, 2011). Indeed, the goal-setting procedures are intricate. In setting goals, the learners need to contemplate the value of the goals, organize the process of methods, consider purposes, monitor personal progress, seek practice opportunities and evaluate the possible outcomes. Goal-setting stands in the starting position of conducting a task. It is recognized that goal-setting is pivotal in learning a second language. Besides, Dörnyei and Otto (1998) further points out that in the actional phase, learners will break down the tasks into small units and set short term goals, while in the post-actional phase, learners reflect the outcomes and adjust their behaviors. These are in accordance with the goal-setting theory and learners apply cognitive strategies to the achievement of the goals. Oxford (2013) ascertains that "the cognitive and metacognitive strategies facilitate understanding (p. 30)". Therefore, the facilitator "task complexity" is put into the "metacognitive \& cognitive strategies" category. In terms of the fourth facilitator "situational constraints", it is in the "environmental" category. Researchers categorize language learning orientations as two: instrumental and integrative (Gardner, 1985, 2006, Gardner \& Lambert, 1959, Masgoret \& Gardner, 2003). The former denotes the practical aspect of acquiring another language. The latter involves learners' desire to learn the language with a view to integrating themselves into the culture of the target language. This taxonomy is constrained by the learning context. In sum, goal-setting is a multi-dimensional practice. Various strategies interplay and interweave in the procedure of achieving the goals. These traits contribute to the multi-dimensional facets of goal-setting.

\subsection{Goal Setting and Academic Performances}

Locke and Latham (2006) propose four mediators about relationship between goal setting and learning performance. They are: (1) Higher goals draw in greater effort than somewhat difficult, easy, or ambiguous goals. (2) Goals can lead people's interest, effort and related behavior. (3) Basic knowledge and skills required for a certain task can have an effect on the goal. (4) Goals can motivate people to use existing knowledge, or drive people to hunt for new one. The aforementioned mediators offer an insight goal-setting. Nonetheless, most of the time setting goals is one thing that draws a lot of attention but later be forgotten. For the goals to be reached, researchers suggest that if learners become assured of the importance of the goal, they are more likely to devote themselves to achieving the goal (Locke, 1996; Locke \& Latham, 2002). In addition, if learners can personally participate in the process of setting goals, the ultimate learning performance will be enhanced (Azevedo, Ragan, Cromley, \& Pritchett, 2002; Griffee \& Templi, 1997; Tubbs, 1986). The reason may be that goals designed and evaluated by the learners themselves are more meaningful (Belliana \& Fogarty, 1991; Moriarity et al., 2001). However, since most learners are young and inexperienced, it is suggested that a combination of student-set and 
teacher-approved learning goals is an optimal strategy. In this case, the learning goal becomes a consensus of both sides. The agreed learning goals have a better opportunity to be achieved (Boekaerts, 2002, p. 18). Researchers suggest improving motivation and performance by setting goals (DuBrin, 2012; Greenberg, 2011; Newstrom, 2011; Schmidt et al., 1996; Schunk and Swartz, 1993). For the results to be higher, the goals need to be specific or challenging (Dörnyei, 2001, Locke et al., 1981, Pintrich \& Schunk, 1996).

Goals navigate the learners in the process of learning. In order to achieve goals, the learners may exploit strategies. Though challenging goals may bring out the potential of the learners, it is suggested to set goals based on the learners' current level of ability. Otherwise, the frustration may make learners less motivated. In L2 motivation, goal setting plays a crucial role. Its influence cannot be ignored.

\subsection{Current Questionnaire Evaluating the Results of Goal Setting}

In the past decades, several studies have been conducted on the use of goal setting. However, there seems to be no instrument that can be applied on a generalized scale. For example, Chang et al. (2013) conducted a study examining the impact of web-based goal-setting mechanisms on self-regulated learning (SRL) in a vocational school. The results showed that web-based goal-setting mechanisms might be able to facilitate SRL. Students who set learning goals through web-based mechanisms made better performance than those with a paper-based portfolio. Vahidnia and Fatemi (2015) conducted a survey on how language learners selected the topic of writing and then discussed the power of goal-setting theory. The participants were 93 EFL students from the Iranian university, who took the writing course. The result showed that there was no significant difference in the choices made by the two genders. Koda-Dallow and Hobbs (2005) explore the relationship between personal goal setting and autonomy in language learning. Participants were 25 first and second year students studying Japanese at BA degree. They were categorized as two, experimental group and control group. Over the five-week period of the experiment, the experimental group set a goal for learning Japanese on a weekly basis, but the control group did not set any objectives. No statistically significant difference between the two groups was shown. The goal setting questionnaire was two folded. One was the questionnaire relating to teacher's and learners' responsibility. The other was a questionnaire of learners' goal setting, with 11 items in the form of a 5-point Likert scale, and 3 other items in the open-ended form.

The above three studies were well-designed, but the numerical facts of validity and reliability of the questionnaires were not provided. Furthermore, goal-setting as a learning strategy and its effectiveness were not mentioned. Due to its special features of goal-setting research, the instruments utilized are usually in the open-ended form. They do provide information for qualitative analysis. However, sometimes the rather superficial and short commitment may bring problems (Dörnyei, 2003). These problems may respond to what Locke and Latham (2004) maintain that goal-setting theory is a cognitive theory that ignores the subconscious mind. As for the practicality of applying questionnaires in a survey, Dörnyei $(2003$, p. 9) pointed out that questionnaires possess the unprecedented attraction with regards to cutting down on three aspects: (a) researcher time, (b) researcher effort, and (c) financial resources. There is no denying that the questionnaire items can serve as a stimulus to help the respondents contemplate their individual situation, and the process in turn subconsciously influences the respondents' behaviors. In Dörnyei (2003), the effect is termed as "acquiescence," indicating the tendency for people to approve with sentences when they are uncertain or equivocal. For language learners who are not equipped with the skills of setting learning goals, the process of responding to the questionnaire can assist them to set realistic and practical learning goals.

\subsection{Purpose of the Present Study}

The study aims to establish a new instrument of evaluating the goal-setting outcomes in learning a foreign language. The instrument should be empirically- and theoretically-based, and the construct represents the multidimensional characteristics of the goal-setting theory. The instrument was subjected to a series of developmental phases before it was finally distributed to the samples to validate its predictive ability. The purposes of the present study are as follows.

1). Constructing a questionnaire of goal setting on language learning, which can serve for quantitative, statistical analyses.

2). Constructing a questionnaire that is with adequate reliability and validity.

3). Construct a questionnaire that is empirically- and theoretically-based and contains the multidimensional aspects - metacognitive, cognitive, social-behavioral, motivational and environmental aspects. 


\section{Method}

\subsection{The Process of Developing the Instrument of Goal Setting}

According to Dörnyei (2003), developing a questionnaire involves several procedures. They are: developing an item pool for each subscale, preparing a first version of the tool, conducting a pilot study for the trial of this version, designing the ultimate version on the results of the pilot study and validating the instrument by making it available to a sample of language learners. In constructing the newly-developed questionnaire, the current study follows the procedures and subsets the procedures into three phases.

\subsection{The Newly Developed Instrument With Multi-Facets-Item Pool Development Principles}

Based on Locke and Latham (2006), the instrument of the present study consists of four facets - task strategies/commitment to the goal, feedback, task complexity and learning goals. In terms of the aforementioned dimensions of goal-setting theory, the first facet "task strategies/commitment to the goal" is a category containing strategies that language learners consciously use to improve their performance and achieve their goals So it is in the cognitive dimension. The second facet "feedback" belongs to the "social-behavioral \& motivational" domain, because feedback is for people to keep record of their change of performance. The third facet of "task complexity" can be categorized into the "metacognitive \& cognitive" dimension because learners need to do something to accomplish the task. The fourth facet "learning goals" pertains to the "metacognitive \& environmental" dimension, in which learners must assess their level and organize their goals based on their current need. Table 1 briefly describes the facets and their dimensions.

Table 1. The facets of the questionnaire and their equivalent dimensions

\begin{tabular}{ll}
\hline Facets of the questionnaire & Dimension represented \\
\hline task strategies/commitment to the goal & cognitive \\
feedback & social-behavioral \& motivational \\
task complexity & Metacognitive \& cognitive \\
learning goals & Metacognitive \& environmental \\
\hline
\end{tabular}

\subsection{The Initial Phase of Developing the Instrument: Drafting the first version of the Instrument}

The first step in this phase was to compile objects that target these facets. Dörnyei (2003) suggested that the involvement of learners themselves in the process of generating items and perceiving their ideas could improve the quality of the item pool. Therefore, in this phase the researchers randomly interviewed three groups, from the first, second, and third grade senior high school students, respectively. Each group consists of eight participants. The interviews were conducted in the students' first language-Mandarin Chinese. Questions like: "Have you ever noted your progress when you work on a task?" "Do your parents offer any praise or award when you make progress?" were included in the interview. The ideas generated from the interview formed a total 14 items on the four facets. All the items included 7-point Likert scales ranging from 1-'strongly disagree' to 7-'strongly agree'. The respondents were required to tick the appropriate box in which the answers best fit their personal experiences. Table 2 lists the final items in the questionnaire.

Table 2. Description of the questionnaire, the categories, numbers and contents

\begin{tabular}{ll}
\hline $\begin{array}{l}\text { Name of the } \begin{array}{l}\text { No of the items in } \\
\text { the category }\end{array} \\
\text { category }\end{array}$ & (1) I will compare my progress with my goals. \\
Task strategies 5 & (2) I have a special strategy for learning English and I think the strategy \\
& is effective. \\
& (3) When I perform tasks and apply my strategies, I observe progress. \\
& (4) If I use it, I will express my strategy in words. \\
& (5) I see the performance of a brilliant person in my class and follow the \\
& example.
\end{tabular}


$\begin{array}{lll}\text { Feedback } & 3 & \text { (1) The effort feedback from others (parents, teachers, and peers) is }\end{array}$ influential, such as the remark, "You got it right because you worked hard."

(2) The ability feedback from others (parents, teachers, and peers) is influential, such as the remark, "You are good at this.

(3) If my learning outcomes are consistent with my anticipation, I will be motivated.

Task 2

complexity

2

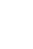

(1) I cut down complex projects into small units and arrange the order of which to perform these tasks.

(2) I will rehearse the things that I need to accomplish several times per day.

Learning goals 4

(1) I would set specific goals for my learning. For example, I would like to memorize 10 new words every day.

(2) I would set general goals for my learning. For example, I would like to gain 10 more points in the next exam.

(3) I would set short term goal for the coming exam. For example, I would like to spend 1 hour studying English every day.

(4) I would set long term goal for my learning. For example, I would like to make progress in 1-semester period.

\subsection{The Second Phase of Developing the Instrument: Evaluating the Instrument by a Pilot Study}

The questionnaire came in two versions-English and Mandarin Chinese. The descriptions in both versions were evaluated by two English grammar teachers and two Chinese literature teachers to ensure that no ambiguous meanings would result in misunderstanding. To help the researchers understand if the instrument was applicable, a pilot study was conducted. The aim of the pilot study was to explore whether the participants had any difficulties comprehending the questions. The researchers recruited around 136 volunteers with the assistance of English teachers from high schools other than where the main study was conducted. The participants were told to ask questions if the descriptions of the items were not clear to them. The administrators took notes if the participants should encounter any comprehending problems. After the survey, the questionnaires were collected and the descriptions were reworded according to the suggestions. And with the results the researcher went on to modify the questions in the questionnaire.

\subsection{The Third Phase of Developing the Instrument: Administering the Ultimate Instrument, Designing and Validating the Questionnaire}

In the third phase, the researcher administered the questionnaires to a different sample. The reliability and construct validity were tested. The participants of the study were 203 junior high school students. The researcher recruited voluntary students through the school online announcement board and received 207 applications. However, four of them failed to appear at the time the survey was conducted. A total number of 203 participants participated in the study. All of them were studying English as a foreign language. To describe their English proficiency level with the vocabulary knowledge, their vocabulary bank size is around 1500-3000 words (Tseng, 2000). The participants here were still in their phase towards fulfilling their requirement; therefore, they were in need of the guidance and training of goal setting skills. The survey was conducted during the one-hour lunch break in the language laboratory. The participants spent 20 minutes approximately to answer the questions.

\section{Results}

\subsection{Reliability}

An internal consistency reliability analysis was conducted. The Cronbach Alpha internal consistency reliability coefficients of the four subscales was revealed in Table 3. On account of the fact that the mean Cronbach Alpha coefficient is 0.89 and all the individual scale coefficients are above 0.70 , we can conclude that the scale was well performed in terms of reliability. 
Table 3. The Cronbach Alpha coefficient of the subscales in the pilot study

\begin{tabular}{ll}
\hline Goal setting & Cronbach Alpha \\
\hline Task strategies & 0.90 \\
Feedback & 0.91 \\
Task complexity & 0.88 \\
Learning goals & 0.87 \\
Mean & 0.89 \\
\hline
\end{tabular}

\subsection{Construct Validity}

The construct validity was evaluated through CFA (the confirmatory factory analysis). The hypothesis that the underlying latent construct of goal-setting was a general factor with four subscales was examined. In the analysis, the software AMOS 22.0 was used. The results from the analysis showed that the correlation between variables was not too close to $1.00(<0.95)$. There were no major standard errors. The results in Table 4 showed that the four subscales were very well discriminated against each other without empirical redundancy. Factor loadings showed good acceptability of construct validity. Regarding overall model fit indices, the goodness-of-fit indices, including Tucker-Lewis Index (TLI), chi-square test to degree of freedom $\left(\mathrm{X}^{2} / \mathrm{df}\right)$, adjusted goodness of fit index (AGFI), goodness of fit index (GFI), incremental fit index (IFI), normed fit index (NFI), comparative fit index (CFI), root mean square error of approximation (RMESA), and Hoelter's critical N (CN), all were evaluated and the results showed that the indices reached the appropriate level of thresholds. The fit indices indicated that the hypothesized model of goal-setting constituted an overall suitable model fit. The results are revealed in Table 4 .

Table 4. The overall assessment of measurement model fit for goal-setting items

\begin{tabular}{|c|c|c|c|}
\hline Index & Levels of acceptable fit & $\begin{array}{l}\text { Results of the } \\
\text { analyses }\end{array}$ & $\begin{array}{l}\text { Assessment of the } \\
\text { instrument }\end{array}$ \\
\hline $\begin{array}{l}\text { chi-square test to degree of } \\
\text { freedom }\left(\mathrm{X}^{2} / \mathrm{df}\right)\end{array}$ & $<3$ & 2.596 & very good \\
\hline Goodness of fit index (GFI) & $>0.90$ & 0.946 & very good \\
\hline $\begin{array}{l}\text { Adjusted goodness of fit index } \\
\text { (AGFI) }\end{array}$ & $>0.90$ & 0.920 & very good \\
\hline Incremental fit index (IFI) & $>0.90$ & 0.979 & very good \\
\hline Normed fit index (NFI) & $>0.90$ & 0.966 & very good \\
\hline Comparative fit index (CFI) & $>0.90$ & 0.979 & very good \\
\hline Tucker-Lewis Index (TLI) & $>0.90$ & 0.973 & very good \\
\hline $\begin{array}{l}\text { Root mean square error of } \\
\text { approximation (RMESA) }\end{array}$ & $0.050<$ RMESA $<0.80$ & 0.058 & very good \\
\hline Hoelter's critical N (CN) & $>200$ & 235 & very good \\
\hline
\end{tabular}

Although the overall model fit shows appropriateness, the proof is still insufficient. Therefore, the exploration of whether the model met the criteria of different internal structural indices is needed. Individual item reliability was computed to test the reliability of the subscales. The individual item reliability of the subscales, i.e. squared standardized factor loading was 0.64 for Learning Goals, 0.71 for Task Strategies, 0.71 for Feedback, and 0.67 for Task Complexity. The recommended threshold value is 0.50 (Bagozzi \& Yi, 1988). The results indicated that the measures fell within the satisfactory range. Besides, all the Critical Ratio (CR) of the parameter estimates were larger than 1.96, representing that all the parameters were significant to the hypothesized model and should remain in the ultimate construct (Byrne, 2001). The suggested ultimate construct together with the factor loadings on each path were revealed in Figure 1. The results from the individual item reliability and the confirmatory factor analysis indicated that the hypothesized model was empirically valid and can function as a basis for investigating the theoretical nature of goal-setting for language learning. According to the result of the 
goal-setting scale, two subscales, "task strategies" and "feedback", play the most significant roles. "Task complexity" comes the third and "setting learning goals" comes the last.

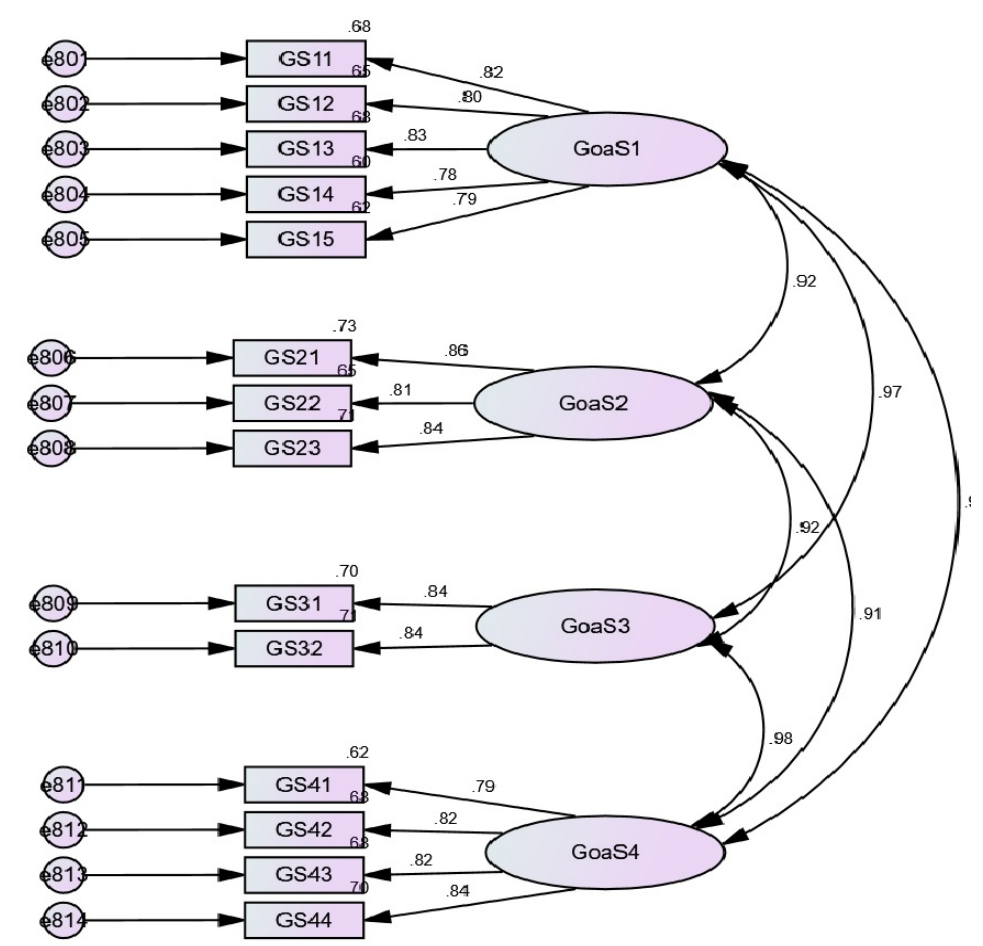

Figure 1. Confirmatory factor analysis of the model of goal-setting

GoaS1 $=$ task strategies; GoaS2 = feedback; GoaS3 = task complexity; GoaS4= learning goals

\subsection{Correlations of the Four EFL Goal-Setting Strategies}

Results of the inter-correlation coefficient offered a clear illustration of how the four EFL goal-setting strategies correlated with each other in the process of setting their goals. The significant correlations indicated that the four categories are distinct and interrelated.

Table 5. Multiple dimensions and inter-correlations of the 4-factor strategies

\begin{tabular}{llllll}
\hline Dimensions & Factors & TS & TC & LG & FB \\
\hline Cognitive & TS (5 items) & 1 & & & \\
Metacognitive \& cognitive & TC (2 items) & $.84^{* *}$ & 1 & & \\
Metacognitive\& environmental & LG (4 items) & $.88^{* *}$ & $.84^{* *}$ & 1 & \\
Social- Behavioral\& motivational & FB (3 items) & $.82^{* *}$ & $.78^{* *}$ & $.81^{* *}$ & 1 \\
\hline
\end{tabular}

Note. $\mathrm{TS}=$ Task Strategies; TC=Task Complexity; $\mathrm{LG}=$ Learning Goals; FB=Feedback;

$* *=$ All correlations are significant at $p<.01$

Metacognitive, cognitive, social-behavioral, environmental and motivational facets interwove and interrelated significantly with each other. This means when EFL learners were contemplating their goals and set the procedures to achieve their goals, they deployed a rich repertoire of various strategies. This lends support to Wolters' (1999: 285) argument that motivational regulation strategies are conducive to "increase students' level of cognitive engagement, ... effort, and subsequent achievement within an academic setting." 


\section{Discussion}

The four categories of the present questionnaire, namely, task strategies, feedback, task complexity and learning goals, are in line with the goal-setting theory. Locke and Latham (2006) address that a learning goal facilitates or enhance metacognition, organizing, monitoring, and assessment of progress toward goal achievement. And they further point out that metacognition is necessary, especially in a place where guidance or structure is minimal, such as in the EFL context. Goals can be set by the instructors or by the learners themselves. For adolescent language learners, goal-setting can be accomplished under the guidance of their instructors or parents. Goals need to be specific so that the learners can recognize the importance of goals and make efforts to attain them. In the item "I would set specific goals for my learning. For example, I would like to memorize 10 new words every day" a specific goal is provided. And the item "I would set general goals for my learning. For example, I would like to gain 10 more points in the next exam" displays the ambition of the learners not merely in learning vocabulary. Apart from setting the goals as learning 10 new words in one day, the learners can also set for themselves different goals in learning the target language. They can make up their daily plan such as reading an English-written passage in the newspapers, watching a film clip on TED channel, listening to the English-speaking programs for one hour on a daily basis, or writing an English composition every week.

The mastery of a second/foreign language requires other knowledge such as comprehension of the articles or mastery of grammar. Well-defined goals help individuals find and apply efficient and effective strategies that influence ways of thinking and behaving (Locke \& Latham, 2002, Smith, Locke, \& Barry, 1990). The short-term goal is set daily, weekly or monthly (Rader, 2005, p. 124). When learners achieve their goals day by day, they also move toward a goal for a longer term, such as a semester. The two items "I would set short-term goal for the coming exam. For example, I would like to spend 1 hour studying English every day," and "I would set long-term goal for my learning. For example, I would like to make progress in 1-semester period" specifically demonstrate the short term as well as long term learning goals for the learners. The instructors may utilize weekly quizzes to track learners' progress and encourage them to set weekly or monthly objectives and lead the learners towards long-term goals for a semester. Nobody can master a skill at the first time. Likewise, in setting one's goals, no individual can fulfill one's plan to the fullest. Sometimes one will be likely to quit due to frustration. The instructor may ask the language learners to get a friend or company to work together. The feeling of working together sustains the drive to move on in the process of fulfilling one's plan.

To achieve effective goals, people need feedback that points out progress (Locke \& Latham, 2002). Feedback provides information about progress in achieving goals. The feedback informs people of what is and the goals disclose what is sought after. (Locke \& Latham, 1990). The goal is also to facilitate the assessment of progress using target standards (Locke \& Latham 1990). For example, if the goal target is to memorize 30 new words in a day, students have to try hard to reach the goal. And if they fail to achieve the goal, they will enhance their effort (Matsui, Okada, \& Inoshita, 1983) or even attempt another means to realize their dreams. The coalescence of goals with feedback will yield more effects than goals alone (Bandura \& Cervone, 1983; Becker, 1978; Erez, 1977; Strang, et al., 1978). Apart from feedback from others, students' self-assessment of the goal acts as the monitor of their progress (Marzano et al. 2001). The three questionnaire items in the category "Feedback" are consistent with this claim. Furthermore, negative feedbacks are likely to bring depression to language learners. The instructor needs to pay special attention to these learners, encourage them to move forward and try to accomplish their learning goals.

Task complexity in Locke and Latham (2006) is defined as the task being complex to the degree that acquisition of task knowledge is relatively difficult. Hence, the learners need to adopt some strategies to accomplish the task For example, when they are required to write an English composition, they need to break down the task into different chunks such as introduction, main body and conclusion in order to finish their assignment on time. Another example is to give an English lecture in front of the class. The learners need to practice the pronunciation, gestures, tone and so on to perform the task perfectly. In the "task complexity" category, there are two items: (1) I cut down complex projects into small units and arrange the order of which to perform these tasks. And (2) I will rehearse the things that I need to accomplish several times per day. The effects of goals rely on the capability of finding appropriate strategies (Locke \& Latham, 2002). Learners tend to find strategies to solve complex task challenges. There are also studies showing that goal-strategy interactions with goal effects are strongest when effective strategies are used (Durham, Knight, \& Locke, 1997). Earley et al. (1989) suggest that urging people to do their best when confronted with complex tasks usually leads to a better strategy. By disassembling the task in small pieces, learners can reduce the difficulty of their work. In addition, repeated movements can add to the strength of the learning effect. Therefore, the "task complexity" category of this category is well suited to the study results. 
With respect to task strategies, five items make up the category, including: (1) I will compare my progress with my goals. (2) I have a special strategy for learning English and I think the strategy is effective. (3) When I perform tasks and apply my strategies, I observe progress. (4) If necessary, I will express my strategy in words. (5) I see the performance of a brilliant person in my class and follow the example. Autonomy is defined as "the ability to be responsible for individual's learning" (Benson, 2001, Dickinson, 1987, Holec, 1981). The above five items show that learners gradually take the responsible attitudes and autonomy (Scharle \& Szabo, 2000). The "task strategies" category in the questionnaire also supports the argument that language learning goal-setting is considered as one of the strategies to promote student autonomy (Locke et al., 1981; Wentzel, 1991; Yang, 1998).

Despite the important role played by language learning goal-setting, it is surprising that few learners have ever been instructed to set learning goals. Bishop (2003) found that $85 \%$ of respondents gave a negative answer to the inquiry of whether they had been taught to set their personal learning goals. Teachers should spend some time training students to set their own objectives. When students have difficulty identifying their goals, Rubin (2015) offers three techniques: (1) identifying students' own problems by reviewing their last practice or exam; (2) determining the type of mistakes they wish to address; (3) identifying some latent goals after learners have written down their problems. Munezane (2015) trains learners to improve goal-setting skills by making a wish to the genie in the fairy tale lamp. The wish works as the goals to be achieved. Hard work and problem-solving strategies help to achieve the goals. Such activities can arouse learners' interest and help them set realistic, achievable goals. Moeller et al. (2012) argue that an intervention to set learning goals should be based on explicit teaching and clarify the relationship between effort and performance. The success of goal setting relies on the consideration of the mediators and moderators, which determine their effectiveness and applicability.

According to Locke and Latham (2006), the number of discoveries made is without limit because goal-setting is an open theory. In their overview of goal-setting instruction for students with behavioral problems, Bruhn et al. (2016) found that, in most cases, students set goals based on their present levels. Therefore, instructors need to pay particular attention to whether learners need to set a new goal. Frequently resetting short-term learning goals can increase learners' motivation and knowledge. The instructor must give the learners the opportunity to evaluate and reflect on their goals and provide constructive feedback in the process of goal setting.

The goals are like dreams. Pursuing dreams is a painful but worthwhile process. In order to achieve the goal, students must appraise the performance after a certain amount of time. They need to pause and evaluate the need to change goals. They can scale the efforts from one to ten and ask themselves what scale they are currently on. Goal setting is just a start. Once the personal goals are set, they need to stay focused, and dedicate their time, energy and efforts to their goals. Goals may vary from one individual to another, and from one period to another. It is necessary to stop and reorganize one's plan, and customize the goals personally. Language learning is a long, painful path. For young learners, the frequent taste of failure will make them quit learning. Many of the learners usually wrongly estimate themselves, either over or under. The instructors need to give them a hand to fight through the negative feeling. Encouraging words can help sustain the motivation. With the help from the instructors, the learners can get a sense of safety and find out the solution to the problem calmly, get over the fear and frustration, reflect their current state and set up a plan for the next stage to achieve their goals. Pain is temporary, but the results are worthwhile and long lasting.

This questionnaire helps the researchers to evaluate the language learners' behavior quantitatively. The respondents can also learn some principles from the descriptions of the items. To sustain goals, L2 motivation serves as the impetus to move forwards. Therefore, future studies can consider investigating the interaction of goal-setting and L2 motivation. To achieve goals, one has to invest efforts and employ strategies. Further studies can include factors such as intended efforts and self-regulatory strategies. Reaching goals can bring the sense of achievement, thus in turn influence one's self-efficacy. Future studies can involve self-efficacy. Negative feedback will bring pressure and hindrance for language learning and turns into language learning anxiety. Future studies can incorporate anxiety and explore its relationship with goal-setting. Last but not least, achievement is another factor remains to be investigated. Future studies can investigate the influence of goal-setting on achievement. The experience of completing the goal-setting plan can be transferred to other areas in life. Hence, setting goals is essential in the life journey. The fatigue and boredom may hinder one's enthusiasm to move on. The commitment is quite crucial in sustaining one's effort. Salancik (1977) pointed out that the ultimate evidence of commitment to a goal is an action taken to achieve it.

The present study attempts to create a goal-setting questionnaire for language learners to conduct a quantitative analysis. In view of their characteristics, goal setting is customized; that is, tailored to individuals. Therefore, the instructor has to consider the uniqueness of each individual and make suggestions to the learners themselves. 
The quantitative elements in the learning goals function as a reference point for the convenience of the analysis. This is the first limitation. Another limitation is that the samples in the study come from high school. The sample students do not represent L2 learners from other educational backgrounds. For learners in other age groups, such as college students, the descriptions in the questionnaire questions need to be changed a bit to fit the sample of other studies. Despite the fact that the instrument developed in the present study has passed the validity and reliability test, the questionnaire may not be suitable for participants from different backgrounds. The limitation results from the feature of the goal setting. Future studies may consider developing a quantitative goal-setting questionnaire by duplicating the process of the present study.

According to Oxford and Shearin (1994), goal setting can have tremendous significance in invigorating learning motivation in L2 (p. 129). The present study aims at constructing a questionnaire of goal setting on language learning, which can suit for the quantitative and statistical analyses. Besides, the questionnaire bears sufficient reliability and validity. Last but not least, this questionnaire is theory-based and the categories have been precisely defined. The data collected can ascertain the relationship between these categories. There is no denying that qualitative research can help explore better about the insights of the participants. Yet quantitative research on goal-setting really increases the convenience of analyzing the large amount of data. The researcher hopes that the design and development of the questionnaire can serve as a useful tool in promoting participants' awareness in setting learning goals and in turn perform better in second language learning. Another hope is to quantify the information collected from language learners during setting goals and make the data available for statistical analyses.

\section{References}

Azar, H. F., Reza, P., \& Fatemeh, V. (2014). The role of goal-setting theory on Iranian EFL learners' motivation and self-efficacy. International Journal of Research Studies in Language Learning, 3(2), 69-84.

Azevedo, R., Ragan, S., Cromley, J., \& Pritchett, S. (2002). Do different goal-setting conditions facilitate students' ability to regulate their learning of complex science topics with RiverWeb? Retrieved from ERIC database (ED482509).

Bagozzi, R., \& Yi, Y. (1988). On the Evaluation of Structural Equation Models. Journal of the Academy of Marketing Sciences, 16, 74-94. https://doi.org/10.1007/BF02723327

Bandura, A., \& Cervone, D. (1983). Self-evaluative and self-efficacy mechanisms governing the motivational effects of goal systems. Journal of Personality and Social Psychology, 45, 1017-1028. https://doi.org/ 10.1037/0022-3514.45.5.1017

Bargh, J. A. (1990). Auto-motives: Preconscious determinants of thought and behaviour. Multiple affects from multiple stages. In E. T. Higgins, \& R. M. Sorrentino (Eds.), Handbook of motivation and cognition: Foundations of social behavior (Vol. 2, pp. 93-130). New York: Guilford Press.

Bellanca, J., \& Fogarty, R. (1991). Blueprints for thinking in the cooperative classroom (2nd ed.). Palatine, IL: IR/Skylight Publishing.

Becker, L. (1978). Joint effect of feedback and goal setting on performance: A field study of residential energy conservation. Journal of Applied Psychology, 63, 428-433. https://doi.org/10.1037/0021-9010.63.4.428

Benson, P. (2001). Teaching and researching autonomy in language learning. London, England: Longman.

Bishop, J. (2003). Empowering students to succeed. NCSC News. Retrieved from http://www.ncsc.info

Boekaerts, M. (2002). Motivation to learn. Educational Practice Series. Geneva: International Bureau of Education.

Bruhn, A. L., McDaniel, S. C., Fernando, J., \& Troughton, L. (2016). Goal-setting interventions for students with behavioral problems: A systematic review. Behavioral Disorders, 41(2), 107-121. https://doi.org/10.17988/ 0198-7429-41.2.107

Byrne, B. M. (2001). Structural Equation Modeling with AMOS: Basic Concepts, Applications and Programming. Mahwah, NJ: Lawrence Erlbaum Associates.

Burton, D., Prickerting, M., Weinbert, R., Yukelson, D., \& Weigand, D. (2010). The competitive goal effectiveness paradox revisited: Examining the goal practices of prospective Olympic athletes. Journal of Applied Sport Psychology, 22, 72-86. https://doi.org/10.1080/10413200903403232

Chang, C. C., Tseng, K. H., Liang, C. Y., \& Liao, Y. M. (2013). Constructing and evaluating online goal-setting mechanisms in web-based portfolio assessment system for facilitating self-regulated learning. Computers 
\&Education, 69, 237-249. https://doi.org/10.1016/j.compedu.2013.07.016

Dickinson, L. (1987). Self-instruction in Language Learning. Cambridge: Cambridge University Press.

Dörnyei, Z. (2001). Teaching and researching motivation. Harlow, England: Longman.

Dörnyei, Z. (2003). Attitudes, orientations, and motivations in language learning: Advances in theory, research and applications. Language Learning, 53(1), 3-32. https://doi.org/10.1111/1467-9922.53222

Dörnyei, Z., \& Ottó, I. (1998). Motivation in action: A process model of L2 motivation. Working Papers in Applied Linguistics (Thames Valley University, London), 47, 173-210.

DuBrin, A. J. (2012). Essentials of management. Mason, OH: Cengage South-Western.

Durham, C., Knight, D., \& Locke, E. (1997). Effects of leader role, team-set goal difficulty, efficacy, and tactics on team effectiveness. Organizational Behavior and Human Decision Processes, 72, 203-231. https://doi.org/10.1006/obhd.1997.2739

Earley, P. C., Connolly, T., \& Ekegren, G. (1989). Goals, strategy development and task performance: Some limits on the efficacy of goal setting. Journal of Applied Psychology, 74, 24-33. https://doi.org/10.1037 /0021-9010.74.1.24

Erez, M. (1977). Feedback: A necessary condition for the goal setting-performance relationship. Journal of Applied Psychology, 62, 624-627. https://doi.org/10.1037/0021-9010.62.5.624

Flanagan, M. J., Putwain, D. W., \& Caltabiano, M. L. (2015).The relationship between goal setting and students' experience of academic test anxiety. International Journal of School \& Educational Psychology, 3(3), 189-201. https://doi.org/10.1080/21683603.2015.1060910

Flower, L., \& Hayes, J. R. (1981). A cognitive process theory of writing. College Composition and Communication, 32, 365-387. https://doi.org/10.2307/356600

Gabb, S. (2001). Authentic goal settings with ABE learners: Accountability for programs or process for learning. Adventures in Assessment, 13, 17-23.

Gardner, R. C. (1985). Social psychology and second language learning: The role of attitudes and motivation. London, England: Edward Arnold.

Gardner, R. C. (2006). The socio-educational model of second language acquisition: A research paradigm. EUROSLA Yearbook, 6, 237-260. https://doi.org/10.1075/eurosla.6.14gar

Gardner, R. C., \& Lambert, W. (1959). Motivational variables in second language acquisition. Canadian Journal of Psychology, 13, 266-272. https://doi.org/10.1037/h0083787

Greenberg, J. (2011). Behaviour in organizations (10th ed.). Prentice Hall International.

Griffee, D. T., \& Templi, S. A. (1997). Goal setting affects task performance. In B. Visgatis (Ed.), Proceedings of the JALT 1997 International Conference on Language Teaching and Learning (pp. 21-26).

Holec, H. (1981). Autonomy in foreign language learning. Oxford, England: Pergamon.

Kato, F. (2009). Student preferences: Goal-setting and self-assessment activities in a tertiary education environment. Language Teaching Research, 13(2), 177-199. https://doi.org/10.1177/1362168809103447

Koda-Dallow, T. \& Hobbs, M. (2005). Personal goal-setting and autonomy in language learning. Proceedings of the Independent Learning Association Conference Inaugural.

Latham, G. P. (2003). Goal setting: A five-step approach to behavior change. Organizational Dynamics, 32, 309-318. https://doi.org/10.1016/S0090-2616(03)00028-7

Latham, G. P. (2004). The motivation benefits of goal setting. Academy of Management Executive, 18, 126-129.

Locke, E. A., Latham, G. P., Smith, K. J., Wood, R. E., \& Bandura, A. (1991). A theory of goal setting and task performance. Englewood Cliffs, NJ: Prentice Hall.

Latham, G. P., \& Kinne, S. B. (1974). Improving job performance through training in goal setting. Journal of Applied Psychology, 59, 187-191. https://doi.org/10.1037/h0036530

Locke, E. A., Shaw, K. M., Saari, L. M., \& Latham, G. P. (1981). Goal setting and task performance: 1969-1980. Psychological Bulletin, 90, 125-152. https://doi.org/10.1037/0033-2909.90.1.125

Locke, E. A., \& Latham, G. P. (1990a). A theory of goal setting and task performance. Englewood Cliffs, NJ: Prentice-Hall. 
Locke, E. A., \& Latham, G. P. (1990b). Work motivation and satisfaction: Light at the end of the tunnel. Psychological Science, 1, 240-246. https://doi.org/10.1111/j.1467-9280.1990.tb00207.x

Locke, E. A. (1996). Motivation through conscious goal setting. Applied \& Preventive Psychology, 5, 117-124. https://doi.org/10.1016/S0962-1849(96)80005-9

Locke, E. A., \& Latham, G. P. (2002). Building a practically useful theory of goal setting and task motivation: A 35-year odyssey. American Psychologist, 57, 705-717. https://doi.org/10.1037/0003-066X.57.9.705

Locke, E. A., \& Latham, G. P. (2006). New directions in goal-setting theory. Current Directions in Psychological Science, 15(5), 265-268. https://doi.org/10.1111/j.1467-8721.2006.00449.x

Manchon, R., Roca de Larios, J., \& Murphy, L. (2007). A review of writing strategies: Focus on conceptualization and impact of first language. In A. D. Cohen, \& E. M. Macaro (Eds.), Language learner strategies: Thirty years of research and practice (pp. 229-250). Oxford: Oxford University Press.

Masgoret, A.-M., \& Gardner, R. C. (2003). Attitudes, motivation and second language learning: A meta-analysis of studies conducted by Gardner and associates. Language Learning, 53, 123-163. https://doi.org/ $10.1111 / 1467-9922.00227$

Matsui, T., Okada, A., \& Inoshita, O. (1983). Mechanism of feedback affecting task performance. Organizational Behavior and Human Performance, 13, 114-122. https://doi.org/10.1016/0030-5073(83) 90115-0

Meader, P. (2000). The effects of continuing goal-setting on persistence in a math class. Focus on Basics, 4(A), $7-10$.

Moeller, A. J., Theiler, J. M., \& Wu, C. R. (2012). Goal setting and student achievement: A longitudinal study. The Modern Language Journal, 96(2), 153-169. https://doi.org/10.1111/j.1540-4781.2011.01231.x

Moriarity, J., Pavelonis, K., Pellouchoud, D., \& Wilson, J. (2001). Increasing student motivation through the use of instructional strategies. Retrieved from ERIC database (ED455962).

Morisano, D., Hirsch, J. B., Peterson, J. B., Pihl, R. O., \& Shore, B. M. (2010). Setting, elaborating, and reflecting on personal goals improve academic performance. Journal of Applied Psychology, 95(2), 255-264. https://doi.org/10.1037/a0018478

Mukherjee, B. (1965). Achievement motivation and goal-setting behaviour in the classroom. British Journal of Psychology, 35(3), 286-293. https://doi.org/10.1111/j.2044-8279.1965.tb01816.x

Munezane, Y. (2015). Enhancing willingness to communicate: Relative effects of visualization and goal setting. The Modern Language Journal, 99(1), 175-191. https://doi.org/10.1111/modl.12193

Newstrom, J. W. (2011). Organizational behavior (13th ed.). New York, NY: McGraw- Hill.

Oxford, R., \& Shearin, J. (1994). Language learning motivation: Expanding the theoretical framework. Modern Language Journal, 78, 12-28. https://doi.org/10.1111/j.1540-4781.1994.tb02011.x

Oxford, R. L. (2013). Teaching and researching language learning strategies (2nd ed.). Harlow, UK: Pearson.

Pintrich, P. R. (2000). The role of goal orientation in self-regulated learning. In M. Boekaerts, P. R. Pintrich, \& M. Zeidner (Eds.), Handbook of self-regulation (pp. 452-502). San Diego, CA: Academic Press. https://doi.org/10.1016/B978-012109890-2/50043-3

Pintrich P., \& Schunk, D. (1996). Motivation in education: Theory, research, and applications. NJ: Merrill Prentice Hall.

Pintrich, P. R., Smith, D. A., Garcia, T., \& McKeachie, W. J. (1991). A manual for the use of the Motivated Strategies for Learning Questionnaire (MSLQ). Ann Arbor, MI: The University of Michigan Press.

Rader, L.A. (2005). Goal setting for students and teachers: Six steps to success. The Clearing House, 78(3), 123-126. https://doi.org/10.3200/TCHS.78.3.123-126

Rubin, J. (2015). Using goal setting and task analysis to enhance task-based language learning and teaching. Retrieved from http://files.eric.ed.gov/fulltext/EJ1080303.pdf

Salancik, G. (1977). Commitment and the Control of Organizational Behavior and Belief. In B. Staw, \& G. Salancik (Eds.), New Directions in Organizational Behavior (pp. 1-54). St. Clair Press, Chicago.

Scharle. A., \& Szabó, A. (2000). Learner autonomy: A guide to developing learner responsibility. Cambridge, England: Cambridge University Press. 
Schmidt, R., Boraie, D. and Kassabgy, O. (1996). Foreign language motivation: Internal structure and external connections. In R.L. Oxford (Ed.), Language learning motivation: Pathways to the new century (pp. 9-70). Honolulu, HI: University of Hawaii, Second Language Teaching and Curriculum Center.

Schunk, D. H. (1990). Goal setting and self-efficacy during self-regulated learning. Educational Psychologist, 25, 71-86. https://doi.org/10.1207/s15326985ep2501_6

Schunk, D. H., \& Swartz, C. W. (1993). Goals and progress feedback: Effects on self-efficacy and writing achievement. Contemporary Educational Psychology, 18, 337-354. https://doi.org/10.1006/ceps.1993.1024

Smith, K. G., Locke, E. A., \& Barry, D. (1990). Goal setting, planning and organizational performance: An experimental simulation. Organizational Behavior and Human Decision Processes, 46, 118-134. https://doi.org/10.1016/0749-5978(90)90025-5

Strang, H. R., Lawrence, E. C., \& Fowler, P. C. (1978). Effects of assigned goal level and knowledge of results on arithmetic compensation: A laboratory study. Journal of Applied Psychology, 63, 446-450. https://doi.org/10.1037/0021-9010.63.4.446

Tartakovsky, M. (2008). Depression and anxiety among college students. Retrieved from http://psychcentral. com/lib/depression-and-anxiety-among-college-students/0001425

Tseng, W. T., Dörnyei, Z., \& Schmitt, N. (2006). A new approach to assessing strategic learning: The case of self-regulation in vocabulary acquisition. Applied Linguistics, 27(1), 78-102. https://doi.org/10.1093/applin/ ami046

Tubbs, M. E. (1986). Goal setting: A meta-analytic examination of the empirical evidence. Journal of Applied Psychology, 71, 474-483. https://doi.org/10.1037/0021-9010.71.3.474

Vahidnia, F. \& Fatemi, A. H. (2015). The advantage of power of goal-setting theory coupled with the power of choice in Iranian EFL learners' writing. Journal of Language Teaching and Research, 6(4), 818-823. https://doi.org/10.17507/jltr.0604.14

Wenden, A. (1991). Learner strategies for learner autonomy. London: Prentice Hall.

Wentzel, K. R. (1991). Social competence at school: Relationship of social responsibility and academic achievement. Review of Educational Research, 61, 1-24. https://doi.org/10.3102/00346543061001001

Winne, P. H. (2011). A cognitive and metacognitive analysis of self-regulated learning. In B. J. Zimmerman, \& D. H. Schunk (Eds.), Handbook of self-regulation of learning and performance (pp. 15-32). New York: Routledge/Taylor \& Francis.

Wolters, C. A. (1999). The relation between high school students' motivational regulation and their use of learning strategies, effort, and classroom performance. Learning \& Individual Differences, 11, 281-299. https://doi.org/10.1016/S1041-6080(99)80004-1

Yailagh, M. S., Lloyd, J., \& Walsh, J. (2009). The causal relationships between attribution styles, mathematics self-efficacy beliefs, gender differences, goal setting, and mathematics achievement of school children. Journal of Education \& Psychology, 3(2), 95-114.

Yang, N. D. (1998). Exploring a new role for teachers: Promoting learner autonomy. System, 26, 127-135. https://doi.org/10.1016/S0346-251X(97)00069-9

Zimmerman, B. J. (1989). A social cognitive view of self-regulated academic learning. Journal of Educational Psychology, 81, 329-339. https://doi.org/10.1037/0022-0663.81.3.329

Zimmerman, B. J. (2011). Motivational sources and outcomes of self-regulated learning and performance. In B. J. Zimmerman, \& D. H. Schunk (Eds.), Handbook of self-regulation of learning and performance (pp. 49-64). Mahwah, NJ: Lawrence Erlbaum.

Zimmerman, B. J. (2013). From cognitive modeling to self-regulation: A social cognitive career path. Educational Psychologists, 48, 135-147. https://doi.org/10.1080/00461520.2013.794676

Zimmerman, B. J., Bandura, A., \& Martinez-Pons, M. (1992). Self-motivation for academic attainment: The role of self-efficacy beliefs and personal goal setting. American Educational Research Journal, 29, 663-676. https://doi.org/10.3102/00028312029003663 


\section{Copyrights}

Copyright for this article is retained by the author(s), with first publication rights granted to the journal.

This is an open-access article distributed under the terms and conditions of the Creative Commons Attribution license (http://creativecommons.org/licenses/by/4.0/). 